\title{
Multiculturalism as a Cognitive Virtue of Scientific Practice
}

\author{
Ann E. Cudd
}

Despite nearly two decades of pathbreaking feminist epistemological research and writing and almost as many years of work on postcolonial and racial critiques of science, the mainstream of philosophical literature has yet to absorb the lessons of this work. I find this especially disappointing because of the inroads made by the social epistemology movement, which now seems to have entered the mainstream of philosophy of science and epistemology. Mainstream philosophers require not merely good arguments but good reasons, stated in their terms, and using their traditions. And being the mainstream, they are able to demand that. In this paper, I shall argue for the lessons of the feminists and marginalized others in the language of the mainstream, making the arguments from the traditions of analytic philosophy. In particular, the lesson I intend to impart is that the dominance of white male Westerners in science impoverishes science on its own terms, and that the inclusion of excluded others will improve the content and the very objectivity of science. In short, multiculturalism is a cognitive virtue (not to mention a requirement of justice) for science.

Foundations denied

Foundationalism in the theory of knowledge is the idea that there are some first principles that can be established to be beyond doubt, and that on them we can justify whatever we are able to call knowledge. Foundationalists oppose skepticism about our knowledge of the external world, but different foundationalists disagree about the source of that ultimate knowledge. However, many agree that our foundational knowledge must come to us as lone thinkers and 
perceivers; we cannot look to society for justification of the knowledge, even if it is in society that we first learn or discover what we come to know. Rene Descartes, in the first of his Meditations on First Philosophy, writes that after becoming aware of all the false opinions he had held from his youth, "I realized that for once I had to raze everything in my life, down to the very bottom, so as to begin again from the first foundations, if I wanted to establish anything firm and lasting in the sciences. ... I have secured for myself some leisurely and carefree time, I withdraw in solitude. I will, in short apply myself earnestly and openly to the general destruction of my former opinions"(Descartes 1980, 57). For Descartes, this project of finding the first foundations of science must be done in solitude because it requires clear thought, unbiased by the ideas or beliefs of others. He needs to wipe his mind clean of the traditional beliefs of his society; what can be known can be discovered by the lone thinker without prejudice from social influence.

Foundationalism of one sort or another has had a long run in epistemology. It is fair to say that it was the going view in much of Western philosophy for nearly three hundred years after Descartes. There is good reason for this: if we can have a firm foundation for our knowledge, then we can justify our beliefs one by one, knowing that justification entails that those beliefs are true, where "truth" is absolute, independent of all observers, for all time. But in the last forty years the foundations have crumbled, and antifoundationalist theories have taken their place in contemporary epistemology. Some of these theories suggest that what we really ought to be doing in epistemology is cognitive psychology: we need to get clear on how our brains gather and sort information, create theories, and decide on evidence. ${ }^{\mathrm{i}}$ This approach is naturalized epistemology. Other antifoundationalist theories suggest that epistemology ought to 
study how persons transmit knowledge within and across cultures, how experts in knowledge production are created, why some forms of systematic information do not count as knowledge, and what standards of objectivity, rationality, and good method are still useful. This approach is sometimes called social constructivism. Finally, a third group of antifoundationalist theories suggests that what we call epistemology is really ideology, that there is no such thing as objective knowledge, and that the word "knowledge" is simply an honorific for the pronouncements of those in power. This is postmodernism. In this paper I shall argue for a conservative version of social constructivism, and shall show that it is a consequence of the social constructivist position that multiculturalism does indeed have something to offer to science on science’s own cognitive terms.

To begin, we need to survey the rise and fall of foundationalism in the twentieth century. The most important foundationalist theory in epistemology and the philosophy of science in the first half of this century was logical empiricism, or logical positivism. The logical empiricists held that the foundation of our knowledge is to be found in perceptual experience, and that our perceptual experience can be rigorously analyzed so as to clear away any dubitable or biased elements. Because the method simply requires attention to observation and adherence to a rigorous, logical method of analysis, it can be employed by a lone thinker. And because the methods of analysis are logical, and hence universal, they are untouched by social, cultural, or moral values. The empiricist theory of perceptual knowledge is phenomenalism; that is, the idea that physical objects are mental (logical) constructions out of sense data. C. I. Lewis held that perceptual experience has two elements: the given and the concept. The given is the noninferential, experiential element of knowledge -- the raw data. The concept consists of the 
judgments we make from this raw data.

To illustrate the difference, imagine a tennis ball. The given element is that part of perception that forces itself on us, that is there for the perceiver who has never experienced tennis or tennis balls, as well as for you and me. The "given" must exist, Lewis claimed, or our perceptual experience would be "contentless and arbitrary" (Lewis 1929, 39). The concept is the judgment "there is a tennis ball." It is also the judgment "there is something solid, spherical, fuzzy, and yellow-green." The concept is equally important, for, Lewis writes, "if there be no interpretation or construction which the mind itself imposes, then thought is rendered superfluous, the possibility of error becomes inexplicable, and the distinction of true and false is in danger of becoming meaningless" (Lewis 1929, 39). While the concept can vary among different perceivers, the given, because it is given by the objects themselves, cannot vary, though we can fail to be attentive to it in all its detail.

A. J. Ayer, in his 1940 book Foundations of Empirical Knowledge, also held a phenomenalist view of perception but, unlike Lewis, was reluctant to try to separate the given from the concept. To talk of the given, he argued, leads us to conflate the perceived and the perceiving; that is, the material thing and the sense-datum. Instead he proposed to keep these distinct by means of a specialized language. This "sense-datum language” is the language of appearances, which describes the perception as it appears to the observer. Looking at the tennis ball, you might say, in sense-datum-ese, "I am having a sensation of a round, yellow-green, fuzzy patch in my visual field." Sense-datum language does not posit the existence of things that correspond to our perceptions, but refers only to that experience that the observer is actually having. Thus "in the domain of sense-data whatever appears is real" (Ayer 1971 [1940], 123). 
For Ayer, the issue of how to interpret perceptual experience is a matter of language, not a matter of fact.

Rudolf Carnap, in his 1928 book The Logical Construction of the World (hereafter LCW), attempted to present a method for logically grounding scientific theories in perceptual data. He contended that legitimate scientific talk can be reduced to talk about experiences and logical constructions out of experiences, and that each of us can do it for ourselves, provided we have a detailed enough description of the logical interconnections given by the scientific theory. The fundamental unit of confirmation of scientific theories is the "protocol sentence," which is a phenomenalistic description of the observer's experience. Carnap proposed a way of reducing scientific theories to their confirming protocol sentences. To test a theory, a scientist was to deduce from the theory a set of observations that would appear to an observer given a certain set of initial conditions. If the observer could affirm the protocol sentences, then the theory was confirmed to some degree. Thus the truth of a theory could be determined, at least to some degree, by its empirical adequacy. Later Carnap replaced the phenomenalistic language with physical descriptions of definite, quantitative, space-time points. He considered this language better because it provided a unique description for all the senses and all observers. But it is important to see that these physical descriptions are just as given as the phenomenalistic descriptions they replaced; only the form of the description has changed.

These foundational theories were constructed to interpret and rationally reconstruct scientific theories. They draw a distinction between the context of discovery, the processes by which individual scientists happen upon their hypotheses, and the context of justification, the empirical and logical method of confirming or disconfirming theories. Justification, but not 
Multiculturalism as Cognitive Virtue - p.6

discovery, is philosophically fathomable. With this distinction these foundationalists claim that science can and should be value-free; that moral and social values are not to play a role in the justification of scientific theories.

The foundational theories of science and perceptual knowledge met serious difficulties around midcentury with the work of Wilfrid Sellars and W. V. O. Quine. Sellars, in his 1956 paper "Empiricism and the Philosophy of Mind," showed that the idea of the given element in experience was a myth. The problem he recognized with givenness can be explained by the following argument. First, it is clear that one thing cannot be at once inferential and non-inferential knowledge, by the law of the excluded middle. The set of noninferential "raw data," which is what we are supposed to receive without conceptualizing, cannot itself give rise to inferences, because it is not yet categorized and therefore not linguistic. ${ }^{\text {ii }}$ The inferential element in perception is the part of the sense-data that is laden with judgment. While we can draw inferences from it, it already is theorized information, not pure data. Thus either the given is noninferential, in which case it cannot give rise to justified knowledge; or it is inferential, in which case it cannot be pure, indubitable, foundational knowledge. Either way, this argument shows that phenomenalism cannot lead us to foundations in empirical knowledge. Furthermore, it suggests that there can be no pure sense-data that are untainted by our own prejudgments; and hence that those prejudgments become interesting subjects of epistemological inquiry in themselves. Appeal to "looks talk" (as in, "this tie looks green") or sense-datum language is of no help here, according to Sellars, because to say that an object looks green, one first has to master the claim that the object is green under some set of standard viewing conditions, and to know how to withhold endorsement of that claim when one is not certain whether the conditions 
are standard. That is, one has first to assume that the gap between sense-data and objects themselves is, in principle, a bridgeable gap, which is just what Sellars's argument denies.

Quine, in his 1953 paper "Two Dogmas of Empiricism," presents another catastrophic argument for empirical foundationalism. The two dogmas to which the title refers are, first, the idea that there is a sharp, and non-theory dependent distinction to be drawn between analytic and synthetic statements; that is, that there are two different kinds of sentences, one that is made true or false by the meanings of the words alone (what Ayer called a matter of language), and the other whose truth conditions depend on empirical facts (Ayer's matter of fact). The second dogma is reductionism, the idea that physical theories can be reduced to observation sentences and analytically connected bridge principles that connect the observation reports to theoretical entities and laws. This is just Carnap's project in LCW.

It seems reasonable to suppose that there is a component of language and a component of fact involved in determining the truth of sentences, and that therefore there should be a continuum of the amount of each in different sentences and thus some sentences in which the factual component is null. Quine, however, showed that there is no neat, nonquestion-begging way of drawing the distinction. He showed this by considering exhaustively the possibilities for defining analyticity and related notions, ultimately showing that they are all defined in relation to each other, and that in order to define any one of them we have to assume an understanding of at least some of the others. Thus he concluded that the analytic-synthetic distinction is a metaphysical article of faith.

The kind of reductionism at issue for Quine is the view that every statement can be translated into a statement about immediate experience. By the time Quine was writing, Carnap 
had given up phenomenalism in favor of physicalism, using as his basic protocol sentences sentences of the form "Quality q is at x;y;z;t'," where x;y;z;t defined a point in space-time. Quine then showed that the reductionist program of Carnap and others requires an undefined element that cannot be eliminated. In the example, the phrase is at had to be the undefined primitive that indicated the givenness of the location. Quine argued that the ultimate problem with reductionism is that it assumes that each sentence in isolation can be confirmed or disconfirmed. In contrast, Quine proposed a holistic view of confirmation of science that has come to be known as the Duhem-Quine thesis: "Our statements about the external world face the tribunal of sense experience not individually but only as a corporate body" (Quine 1980, [1953] 41).

The two dogmas are closely connected. Quine even claims that they are "at root identical," because they both depend on the idea that the truth of a statement is completely analyzable into a factual and a linguistic component. (As we have noted, Ayer traded on this analysis.) Reductionism concerns the truth conditions of the factual component; analyticity the linguistic component. In both cases, the mistake stems from the idea that the unit of empirical significance is the statement or the term, when actually it is the whole of experience. Thus, when we confront an experience that contradicts our beliefs or our theories, we have many possible options: we can reject the belief or theory, or we may readjust some of our other beliefs to account for the anomalous experience. Once we accept holism, however, we come to see that the truth of theories is not uniquely determined by their empirical adequacy. Sense data come to us already informed by our theories and not as raw data, and we reinterpret experience in light of our whole belief system. Therefore, no one experience by itself counts against or for 
a theory without all sorts of other background assumptions. Given enough readjustments in our belief system, we can retain any theory in light of any experience. This means that our theories are underdetermined by the empirical evidence we have for them. We need to bring other values to bear in judging our scientific theories, values such as internal consistency, simplicity, and coherence with other beliefs and values.

Thus the history of epistemology in the first half of the twentieth century was marked by a great optimism for empirical foundationalism grounded in a logical analysis of language and theories, and by a subsequent rejection of that foundationalism. The resulting holism or pragmatism left epistemologists to search for new criteria of adequacy for theories or knowledge claims. Unless one can hold that the data reveal the hypotheses themselves, there is an epistemological gap between the evidence from the data and the hypotheses. This gap is filled by background assumptions, including values, some of which, like the theoretical values of simplicity and coherence, are more or less consciously held by scientists, and some of which lie hidden from them.

Epistemology without foundations: social constructivism

The demise of empirical foundationalism leaves philosophers with the task of formulating new approaches to belief formation and justification. But the distinctions between the process of belief formation, the context of discovery, and the context of justification now blur. Justification cannot be viewed as a logical pursuit, free from the context of the scientists, for their culturally shaped background assumptions help determine how they gather and interpret evidence and assess theories. That is to say, justification comes to be much like belief 
formation, and therefore subject to the same contingent and value-laden motivations and background assumptions as the context of discovery.

Postpositivist philosophy of science has therefore focused much more on the process of discovery and the practices of theory testing and analysis, trying to locate in these practices some identifying feature of the activity. Postfoundationalist epistemology tries to justify confidence in that activity as a source of knowledge. One important postfoundationalist epistemology that I shall defend is social constructivism. This is the thesis that knowledge is essentially a social construction; that knowledge production is governed by a set of social norms that are justified within a community of knowers but that cannot be justified outside of all social norms or communities. Knowledge, then, is relativized to the society in which it is produced and sanctioned. But social constructivism does not give up the idea that knowledge production can be objective. Helen Longino, in her book Science as Social Knowledge (1990), presents a version of a philosophy of science that would correspond to a conservative reading of social constructivism with what she calls contextualist empiricism.

Contextual empiricists hold that the relation between theory and evidence contains a logical gap. Evidence for a theory does not come with a label that explains what the data are or what they show; to believe otherwise is to fall prey to the myth of the given. To interpret data as evidence for or against a particular theory requires some background assumptions. For example, I come home around five o'clock, put my bicycle in the barn, and see three other bikes there. From this I reason that my partner must be home. Three bikes in a barn does not naturally mean he is home; I infer this because I have a particular set of background beliefs: that he goes places with his bike, that he does not have the habit of going for a walk alone in the 
evening before I get home, that if he were doing something unusual this evening he would have told me about it, and so forth. Now if I had slightly different beliefs, I might have inferred some other hypothesis, for example that he had not ridden his bike to work that day. The logical gap between data and evidence and between evidence and theory is filled by such background assumptions. In addition, our interests guide us toward certain questions and issues. I might have inferred from the three bikes in the barn something about the number three, about the absence of bike thieves in the neighborhood, or about the amount of space left in the barn for other outdoor equipment. But I was not interested in these things; I was interested at the time only in whom I might find in my house. These background assumptions and interests which determine how data are relevant for us, are not, even in principle, specifiable in complete detail.iii What sorts of things count as background assumptions? The psychological answer is that anything goes — political values, moral values, prejudices, causal beliefs, warranted and unwarranted assumptions of all sorts. There is no limit. The kinds of things that the positivists thought were influences only in the context of discovery turn out to play a role in the crucial justificatory practices of finding evidence and testing theories. Epistemologists are not usually primarily interested in the psychological answer, though. They want to know what the legitimate influences are.

The background beliefs that come into play cannot all be transparent to the investigator or her peers. This is because not all of our beliefs are transparent to us, and any of them can play a role. It is difficult to give examples of current scientific theories that contain such hidden beliefs, because if I can name them they are not very hidden anymore. But we have many historical examples. Take chemists in the seventeenth century. One of their background 
beliefs (of which they were not aware) was that anything we could see had to be a substance. Flames had to be substances; and so they posited phlogiston. Because of the unavoidable influences of background beliefs that are invisible to the scientist, scientific knowledge is relative to the beliefs of the scientific community, which are in turn influenced by the larger.

This is a problem if we think that the goal of science is to ascertain the truth in a correspondence theory sense of truth. The contextualist empiricist takes the internal goal of science as to extend its explanatory theories to wider arrays of phenomena, and to be coherent with what the community takes to be the known facts. Science is characterized by an attempt to interpret empirical phenomena through experimental testing or similar confrontations with data. While truth may not be ascertainable, it can become clear when personal preferences or social biases lead to false, incoherent theories. So science must also aim to clear out personal preferences and pernicious prejudices that hinder its pursuit of coherent, fruitful, empirical explanation.

Science, on the contextualist view, is an essentially social activity in at least three senses. $^{\text {iv }}$ First, it is the product of many people working together, and of different groups of people repeating, criticizing, and amending each other's theories. John Hardwig has pointed out that many experiments in physics now require dozens of collaborating scientists, no one of whom can understand entirely the details of the experiments or the conclusions reached from them (Hardwig 1991). They are essentially group projects, as is their acceptance and understanding by scientists. Second, scientists undergo a common educational process. They are trained in the same canon of examples and solutions; they share the same literature, beliefs, and epistemic values. Furthermore, they typically are socialized into the same or similar 
culture, and so share a set of background cultural interests and values. Third, in an obvious and political sense science is social because it depends on the support of the larger society for funding. This is much truer today than it was in previous centuries, since it has become so much more technology dependent and therefore expensive. Science is supported by government, industry, and to a lesser extent, private philanthropy. Large groups of people spend significant amounts of time deciding what are useful proposals for investigation, and so what questions will be asked, what experiments will be run, what field observations will be made, what techniques will be perfected, and when a research program has run its course. Both the background assumptions and the interests of scientists are socially generated, and socially expressed through funding decisions.

Given these social features of scientific enterprise, plus the the general agreement that science funding is a public good, and that science plays such a critical role in the development of society, justice clearly requires that as a society we offer equal opportunity to persons of all races and genders to create and influence the direction of science. My project here, though, is to show that multiculturalism has cognitive benefits for science. I argue that science will be better off, by its own internal goals, if society pursues a policy of multiculturalism within science and a policy of race and gender equality in the society as a whole. While positivists could agree that justice requires society to pursue policies that diversify the population of scientists, they would disagree that this has anything to do with the epistemic goals of science. To see how the contextual empiricist justifies the claim that it does, we now need to examine further the character of science.

The empirical foundationalists believed that objectivity was guaranteed by adhering to 
strict standards of rigorous hypothesis testing by evidence. If a theory were a false description of reality, an anomalous experiment sooner or later would reveal that. All the scientist had to do was to design experiments that would expose the truth would and to be open to interpreting the data correctly. In the contextual empiricists view, there is no such neat relationship between theory and evidence; instead, the social character of science can make it objective. Because they concede that knowledge is relative sociologically or historically, contextual empiricists do not therefore concede that scientific knowledge is subjective, or that anyone's beliefs are as good as anyone else's. To see this, we need to focus on knowledge formation processes, or the practices of scientific investigation.

By practices, I mean everything from the education of graduate students to the laboratory and field procedures of peer scientists, to the funding decisions of peer reviewers. The first thing to notice is that the social character of science makes it public knowledge in two senses. First, its theoretical assumptions, methods, and even background assumptions are available to anyone who undertakes the same training and immersion in science. Second, its evidence and explanations may be subjected to review and criticism by all who have this training and background. The same things cannot be said of mystical or emotional experiences, which are clearly subjective experiences. Science is self-critical; it proceeds by critical review of hypotheses and of the relevance of evidence to the hypotheses. In the latter way, especially, background assumptions are revealed and questioned and sometimes modified.

Longino uses a poignant example from the history of physics to illustrate this questioning of background assumptions and the consequent progress of science. Before Einstein's relativity theory took hold, physicists believed that light was propagated through a medium called the 
"ether." (They believed that all waves had to be propagated in some medium.) The Michelson-Morley experiment was supposed to measure the relative motion of the earth in the ether by the difference in the speed of light beams sent out at 90 degrees from each other. That difference could be inferred from the shifts in the interference fringe the beams produced on an interferometer. However, no significant displacement of the interference fringe took place. Some physicists interpreted this null result as a confirmation of the Lorentz-Fitzgerald contraction hypothesis. By criticizing the background assumption of the existence of the ether, however, relativity theorists were able to abandon that assumption and make a significant advance in physical theory. Science often progresses in this way by challenging the background assumptions that an experiment was not originally intended to test (Longino 1990, chaps. 3-4). These challenges come often not from the scientist who develops the experiment but from others, who can see the underlying background assumptions but do not share them. The point is that the objective character of science comes from its practice of public, intersubjective, critical review. But how can scientists critically assess their collective assumptions to root out personal preference and pernicious prejudices that hinder progress in the sciences when these preferences and prejudices are themselves socially influenced and maintained?

\section{Perspectives of the oppressed}

Longino explains well how background assumptions sometimes need to be rejected to move forward toward a better, more coherent, more fruitful explanatory theory. In her book, she argues that culturally based prejudices against women have led scientists to make assumptions, for example, of universal male dominance, which not only turn out to be false on 
direct examination but also to cause to misinterpretation of data and the construction of bad theories. Still, this does not tell us how generally we can influence science to discover its hidden assumptions that are based on social prejudice.

Sandra Harding's notion of strong objectivity helps here. She claims that the main problem with the positivist notion of objectivity, which she terms "objectivism," is that it fails to recognize that when science or other knowledge-producing institutions are practiced by only a privileged section of society, they will overlook the same observations and problems with the theories that the practitioners would tend not to notice. The result is not only bad science, but also further oppression and mystification of what knowledge is and how it is produced. The solution, Harding argues, is to begin with those observations that are invisible to the privileged elite, in order to formulate new research programs and possibly new methodologies. In Whose Science? Whose Knowledge? she writes that in "a society structured by gender hierarchy, 'starting thought from women's lives' increases the objectivity of the results of research by bringing scientific observation and the perception of the need for explanation to bear on assumptions and practices that appear natural or unremarkable from the perspective of the lives of men in the dominant groups" (Harding 1991, 150). The scientist should begin from the lives of the oppressed to gain a better understanding of phenomena, and the epistemologist also should do so for a better understanding of knowledge formation processes.

One might object that this leads to a vicious regress of victimology, in which the most oppressed have the purest possible epistemic position. One need only consider the implication that the elderly atheist lesbian woman of color with AIDS would have to be the best physicist to see how absurd such a position would be. But Harding does not fall prey to this objection, 
because she recognizes that not just any observations of the lives of the oppressed will be helpful. Harding argues that the epistemologist or scientist who "begins from the lives of the oppressed," by which she means someone who recognizes the social nature of the oppression, has a less distorted picture of reality than the rest of us. According to Harding, "women's experiences in themselves" do not necessarily provide reliable grounds for knowledge claims. Thus her distinction between beginning from “women's lives” and taking “women's experiences” for granted.

Starting from women's lives does not mean taking for granted what women say about them. Instead, we examine women's situation from a theoretical, critical understanding of patriarchy, racism, and imperialism; that is, from a feminist and multiculturalist standpoint. As an example, Harding mentions our understanding of rape within marriage, which, before the feminist movement, could not have come from women who thought rape in marriage a conceptual impossibility even while they suffered from it. It was only when we could see women as oppressed through marriage, and as having human rights despite being in that institution, that we could see marital rape as a conceptual possibility. If we take seriously the notion that all observations are theory laden, and we accept that some oppressed persons have mistaken or underdeveloped theories about their lives, we recognize that there are better and worse ways of understanding the experiences of the oppressed. Equally, however, we notice the experiences of the oppressed only when we observe the lives of the oppressed with a sensitivity to their oppression. That requires us to observe from the perspectives of the oppressed. It is quite plausible that the members of oppressed groups themselves would be more successful than the rest of us in making science take the perspectives of the oppressed into account. Therefore 
it is a plausible consequence of Harding's arguments that science benefits from oppressed persons' actually entering science. Harding's concept of strong objectivity builds in contextualism, requiring that the perspectives of the oppressed be mediated through theory. In this way she avoids committing the multicultural version of the myth of the given by taking the data of the oppressed to have immediate, natural significance.

Instead of the lone thinker seated before the fire, the metaphors that best fit the social constructivist epistemologist are Neurath's metaphor of the boat that one must constantly rebuild while one is afloat in it, and Rawls’s reflective equilibrium between theory and practical application. Social constructivists must take the perspective of the oppressed but reconstitute that data using critical social theory. In the face of enough contradicting evidence, they must also alter their theory to be consistent with their observations of the oppressed. They rebuild their boat, trying to maintain an equilibrium between scientific theory and personal observations of the oppressed, and this makes their view of the world less distorted, less partial, than others'. To reformulate Descartes’ passage in light of these epistemological lessons, we realize that we cannot raze everything in our lives, down to the very bottom, so as to begin again from the first foundations. If we want to establish anything firm and lasting in the sciences, we should come together in all our diversity critically to assess our collective background assumptions. We should, in short, apply ourselves earnestly and openly to generally destroying our former opinions when they turn on assumptions that, we now can see, lead to incoherent theories.

There are two senses in which multiculturalism has something to offer science, if this view of objectivity is correct. First, when science pursues social policies that will bring people of color and women, false assumptions based on prejudice against these groups will become 
noticeable and subject to critical inquiry. Thus multiculturalism as a social project of ensuring diversity and equality will itself lead to better science. Because strong objectivity does not require one actually to be a member of the oppressed in order to begin from the lives of the oppressed, nearly all scientists are likely to gain a better understanding of the ideological motivations of their theories under the influence of multiculturalism. Second, those scientists who are members of oppressed classes will be most likely to question and critically assess background assumptions that degrade, defame, or otherwise harm their members. Thus multiculturalism, considered as a broader representation of the human experience in science, will lead to better science.

An important question at this point is where will multiculturalism make a difference. Will it make a difference in physics, biochemistry, the foundations of economic theory? Or will it only make a difference in those theories that directly deal with race, sex, or gender? Scientists and philosophers have only just begun the difficult work of showing where beginning from the lives of the oppressed is useful and where it is not. I have little hope for a general solution to this question; it seems likely that it will turn out to be an empirical question in every case. ${ }^{v}$ If it does, then we need to look at work that attempts to build new theories from the perspectives of the oppressed. There have been some significant results in all of the social and biological sciences and in the philosophy of science, if the general line of argument of this paper is correct. The effects have been far wider ranging than simply theories about race or about sex or gender, though I hasten to add that given the right interests, these theories alone can be a significant portion of the social and biological sciences. Two examples from the science most familiar to me, economics, show how bringing in a multicultural presence and sensitivity has changed 
theory.

Feminist Economics of the Family

Even though "economics" comes from the Greek oikonomikos, referring to household management, economic theory has often neglected the family in the past. Today we still see textbooks in which lists of important social institutions overlook the family (Ferber and Nelson 1993, 5). In the history of the discipline, we can see three models of the family: the father-as-dictator model, the aggregated household model, and recently, under the influence of feminist economics and the women's movement generally, the competing-but-unequal-agent model. The first of these we can be traced at least to Hobbes, but perhaps is best summarized by James Mill:

One thing is pretty clear, that all those individuals whose interests are indisputably included in those of other individuals may be struck off without inconvenience. In this light may be viewed all children, up to a certain age, whose interests are involved in those of their parents. In this light also, women may be regarded, the interests of almost all of whom is involved either in that of their fathers or in that of their husbands. (Quoted in Folbre and Hartmann 1988, 188)

This model assumes that women need protection by sovereign men, and that men will provide this protection without undue selfishness. This makes attention to the family unnecessary theoretically; economic theory can assume that individuals are male and that whether they have wife and family is irrelevant. 
In the 1960s economic theory began to look at households with what is called the "new home economics." The 1992 Nobel Prize in Economics was awarded to the founder of the new home economics, Gary Becker of the University of Chicago. Becker's motivation was to try to apply economic theory to all sorts of behavior that mainstream economics had overlooked: crime, animal behavior, and drug use, among others. Becker argues that the family is guided by altruism, and that it acts to maximize total household utility. He first endows each member of the family with an individual utility function that she or he tries to maximize. Then he shows, in the Rotten Kid Theorem, that if there is an altruistic family member—by which he means a member whose utility function has other family member's utilities as arguments-then it is rational for the selfish family members to maximize total family utility as well (Becker 1981). Thus he derives the patriarchal family as an invisible-hand-result of each person pursuing her own good.

Well, there is no arguing with mathematics. But how shall we interpret this theory of the family? Somewhat concealed by the mathematics are three other critical assumptions. First, wealth or control of income is unequally distributed, so the altruist is able to redistribute income to maximize his utility function (I use "his" here because Becker quite explicitly assumes that the altruist is the father). Second, it assumes that the egoists in the family (including the altruist's wife) have no better option than the one the altruist gives them. Third, the use of the positively ethically loaded term "altruist" presumes that his utility function ought to be maximized. Becker thus confirms the older economic view of the family as a unit, a single individual, represented by an altruistic "head." He thereby shows that there is no theoretical need to look inside those families. In such a situation, there is no need for the intrusion of law; what Rawls 
calls the "circumstances of justice" do not arise because ultimately there is no competition for resources. The father's paternalistic wishes must be fulfilled. Equality is not an issue.

Becker believes that marriage evolved as a deal to protect women, and his model of the family seems to confirm that view. Women can be seen as making a kind of Hobbesian deal: trading the promise of security for subjugation to sovereign power. However, as feminists have been pointing out, the claim that marriage protects women does not square with the empirical evidence that it exploits and oppresses them, for instance, by longstanding, socially sanctioned spousal abuse. Married women were, until relatively recently, prohibited from owning property, subject to unequal divorce laws, and affected by countless other laws and norms that constitute the double standard for married men and women.

If his work is so faulty, how do we explain Becker's Nobel Prize? His theory is just what the dominant strain of economists (in terms of theoretical as well as political commitments) love: it extends the neoclassical economic approach to a new area, the family, yet appears to vindicate the longstanding tradition of overlooking intrafamily economic issues, while justifying the political status quo concerning gender relations. Thus, the comfortable, sexist, gendered, political ideology for economists lends the theory cognitive authority that it did not warrant scientifically.

Since the 1980s a growing number of feminist economists have uncovered these hidden assumptions and interests behind economic theories of the family. ${ }^{\text {vi }}$ By paying attention to the inequalities in marriage and the consequent harm to women, they have been able to develop theories that can help guide social policy to address those harms. The models these economists have developed are versions of what Amartya Sen calls the cooperative conflict model. In this 
model, each person maximizes her or his expected utility, recognizing the gains to be won from some cooperation and, at the same time, the conflict of interests among the agents. Each spouse tries to maximize her or his own utility, there is a pool of goods to allocate, and each must agree to the allocation, on pain of the breakdown of the relationship. Some readers may object that this model views families as the site of conflict rather than cooperation. But that objection misses the point that all cooperation is ultimately motivated and justified ultimately by the interest of each party in the cooperation. If there were no such interest for any member of the cooperative group, then that member would be acting against her interests; that is, she must be exploited or coerced. This model reveals the degree to which each person's interests are satisfied, and thereby allows comparisons between spouses. With the addition of general, gender-related features of the economy, this kind of model reveals institutionalized gender inequality in the society.

The point of this example is to illustrate how hidden background assumptions about gender and economists' interests lead to different theories. In the earlier models, the economists assumed that men would head households, the best arrangement for all concerned. This allowed economists to overlook injustices in families and even to assume that families were uninteresting economic institutions. Feminist economists and the women's movement, which raised society's sensitivity to issues of gender inequality, revealed the falsity of those assumptions. Furthermore, women economists have a direct interest in revealing gender injustice. The result is a more nuanced theory of the family that fits much more of the data about gender and that can guide social policy regarding the family. 
The Political Economy of Famines and the Career of Amartya Sen

Until the groundbreaking work of the Indian economist and philosopher Amartya Sen, beginning in the 1970s, famine had not been a major concern of economic science since the eighteenth century. Until Sen’s work, it was dogma among economists that famines were caused by food shortages or overpopulation and that free-market mechanisms would, if left unhindered by government interventions, solve the problem by supplying food in the region and at the localities where demand was greatest. Sen, who as a child had witnessed the Great Bengal Famine of 1943, showed, through statistical research, that famines often happen when there is no shortage of food in the region where people are starving, and that famines happen in times of economic boom (the Great Bengal Famine was an example) as well as economic decline. (Sen 1981) Sen was been able to show theoretically how market mechanisms can thwart relief efforts. Indeed, during many famines food can be seen being exported from the affected region. This happens because the people who need the food cannot "demand" it in the economic sense; that is, they have no legal entitlement to it because they cannot pay for it (Sen 1981, p.161). Sen's theory of famines is that they are failures of entitlements, not food shortages.

As a result of his work on famines, as well as his more general concerns with microeconomic theory, Sen has developed a theory of capabilities that rivals the expected utility theory on which current, neoclassical economics is founded (Sen 1987; Nussbaum and Sen 1993). While utilities are essentially expressions of subjective preference, capabilities measure individuals’ objective abilities to attain goods.

Sen’s career as an economist has been nothing short of stellar. He has made original and 
important contributions to fields as diverse as social choice theory, welfare economics, development economics, economics of the family, and microeconomic theory. ${ }^{\text {vii }}$ His work is as broad as Gary Becker's, and in many ways deeper. In addition, Sen is surely the subtlest and most important philosopher among the economists. He is celebrated widely as both. Yet as of the writing of this article, he has never won the Nobel Prize for Economics. There are, I think, two main reasons for this. First, he has a multicultural and feminist outlook, expressed in his work through his choice of problem areas and his selection of collaborators. Second, his keen philosophical mind leads him to question basic assumptions of economic theory. In particular, his criticism of utility theory, especially the revealed preference form of it, alienates many economists. Much of his work is seen as leading in mathematically intractable directions, and this diverges from the current passion for mathematics in economics. Although these reasons are not directly connected to his being non-white (the Nobel Prize in Economics has had one previous non-white winner, Sir Arthur Lewis, 1979), I think there is an indirect connection in the sense that his work is not seen as mainstream. Instead, with the exception of his work on social choice theory, it diverges a bit from the main interests of economics; one is tempted to say that it is too ethnic. I find it somewhat ironic that famine and hunger could fail to be a central concern of economics.

Sen’s work on famines and on capabilities illustrates how a multicultural outlook and experience can lead to productive new fields of research and to new theories in old territory. Of course, it might be argued that Sen is simply a genius, and that genius, from any cultural background or either gender, will bring about novel and productive work. While this may be true, it is also undoubtedly the case that Sen's direct experiences with colonialism and famine led 
Multiculturalism as Cognitive Virtue $-\mathbf{p . 2 6}$

him to his analysis of famines as caused by political and legal structures rather than by shortages of food.

\section{Objections}

There are two kinds of objections that I want to address in conclusion. The first is what I call the "Barbarians At the Gate" objection. Social constructivism degenerates into a subjective relativism, which holds that all knowledge is partial to some person or group of persons, and that there is no real hope for objectivity. The best we can achieve is recognition of the partiality of our own theories. "Knowledge" is a term that those in power use to "privilege" their beliefs and desires, and hence to justify their continued power over others. "Science," likewise, simply names the practices they use to reap a greater share of social goods than others, and to develop technology that serves the interests of the powerful. However, I have argued that it is possible to hold on to contextual empiricism and not have to give up the claim that science proceeds objectively, though it is not the unique form of inquiry to do so. The relativist suggests that what needs to be done is to support all claims to knowledge, perhaps then to combine them to find the least partial truth by combining the most sources of data. But it makes all the epistemic difference what we do with our data in this regard: what counts as data, how much weight each piece of data gets, how we reconcile apparently inconsistent data. Answers to these questions are difficult theoretical issues, I grant, and the questions have been answered in the past in ways that further oppress certain groups. But they must be answered to get anywhere at all. Contextualist empiricism's form of social constructivism offers this answer: the scientists themselves decide in open debate about the simplicity, empirical adequacy, and 
coherence of the resulting theories, and questions about cultural, class, or gender bias are not ruled out of court.

The second objection is what I call the "So What?" objection. It is the claim that my view of what multiculturalism has to offer science is merely a practical point about doing science, not an epistemic point. I have two responses here. First, to call it "merely" a practical point is a mistake. Science is largely constituted by its practices. To say that its practices need to be changed because that will make a difference in terms of the theories we will accept seems to me a major point. So I would challenge the dichotomy of epistemic and practical values that lurks in this objection. Second, this objection does not properly recognize the epistemological gains. The argument I have made is that social and cultural values and group-related interests play a role in the direction of research and in what counts as fact. This latter point especially deserves emphasis. If what counts as a fact, as a relevant phenomenon to be explained by a theory, is determined partly by the social groups who are allowed to be scientists, then what counts as a good, confirmed theory will depend also on who the scientists are. I just fail to see how this could not be an epistemological point.

Multiculturalism will lead to better science, by science's own criteria, than we have had with a race- and gender-exclusive community of scientists. I have argued that this is true for two reasons. First, the minority and women scientists themselves will be more likely to recognize the false, prejudiced assumptions about race and gender that have lurked in the background, guiding scientists as they interpret evidence and build theories. Second, the kinds of changes that society will undergo in pursuing multiculturalism will help reveal these faulty assumptions and change the interests of scientists of all races and genders. The interests of truth 
and justice come together in the demand for diversity in science.

\section{Notes}

Earlier versions of this paper were presented to audiences at Wichita State University and Occidental College. I thank the Philosophy Departments of those institutions for the opportunities to present my work, and the audiences there for helpful discussions. I am also grateful for the thoughtful comments of Sandra Harding and three anonymous reviewers for Hypatia.

1. The locus classicus of this approach is Quine 1969. See also Kornblith 1985; Antony 1993.

ii. This point was understood by Locke and by Berkeley, as well, as their blind man who suddenly regains sight. See Locke 1975, 52; Berkeley 1979, First Dialogue.

3. This claim comes from a thesis in cognitive science known as the "frame problem," which says that there is no principled way of delineating every possible relevant fact for making inferences from data.

4. I owe the original description of these three senses to Longino 1990, chap. 4.

5. See Anderson 1995 for several illustrative examples of the mistakes that feminist scientists have uncovered,

vi. See McCrate 1987; Sen 1984; McElroy and Horney 1981; Manser and Brown 1980. 
7. In social choice theory, Sen is responsible for the theorem stating the "impossibility of a paretian liberal" and for various criticisms of the Pareto Principle; in welfare economics, he is best known for his analysis of measurements of welfare outcomes; in development economics, his theory of famines is his best-known achievement; in microeconomic theory he is best known for his criticism of revealed preference theory and his theory of capabilities. Articles containing many of these contributions are collected in Sen 1982.

\section{References}

Anderson, Elizabeth. 1995. Feminist epistemology: An interpretation and a defense. Hypatia 10(3): 50-84.

Antony, Louise. 1993. Quine as feminist: The radical import of naturalized epistemology. In $\underline{\mathrm{A}}$ mind of one's own, ed. by Antony and Charlotte Witt. Boulder: Westview Press.

Ayer, A. J. 1971 [1940]. The foundations of empirical knowledge. London: Macmillan.

Becker, Gary. 1981. A treatise on the family. Cambridge: Harvard University Press.

Berkeley, George. 1979. Three dialogues between Hylas and Philonous. Indianapolis: Hackett. Carnap, Rudolph. 1967 [1928]. The logical construction of the world. Trans. Rolf A. George. Berkeley: University of California Press.

Descartes, Rene. 1980 [1641]. Meditations on first philosophy, trans. Donald A. Cress. Indianapolis: Hackett.

Ferber, Marianne A., and Julie A. Nelson. 1993. Beyond economic man: Feminist theory and economics. Chicago:University of Chicago Press.

Folbre, Nancy, and Heidi Hartmann. 1988. The rhetoric of self-interest: Ideology and gender in 
economic theory. In The consequences of economic rhetoric, ed. Arjo Klamer, Donald N.

McCloskey, and Robert M. Solow. New York: Cambridge University Press.

Harding, Sandra. 1991. Whose science, whose knowledge? Ithaca: Cornell University Press.

Hardwig, John. 1991. The role of trust in knowledge. Journal of Philosophy 37(12): 693-708.

Kornblith, Hilary. 1985. Naturalizing epistemology. Cambridge: MIT Press.

Lewis, C. I. 1929. Mind and the world order. New York: Scribner’s.

Locke, John. 1975 [1689]. An essay concerning human understanding. Oxford: Clarendon Press.

Longino, Helen. 1990. Science as social knowledge: Values and objectivity in scientific inquiry.

Princeton: Princeton University Press.

Manser, Marilyn, and Murray Brown. 1980. Marriage and household decision-making: A

bargaining analysis. International Economic Review 21(1): 31-44.

McCrate, Elaine. 1987. Trade, merger and employment: Economic theory on marriage. Review of Radical Political Economics 19(1): 73-89.

McElroy, Marjorie B., and Mary Jean Horney. 1981. Nash-bargained household decisions:

toward a generalization of the theory of demand. International Economic Review 22(3):333-349.

Nussbaum, Martha, and Amartya Sen. 1993. The quality of life. Oxford: Oxford University Press.

Quine, W. V. O. 1969. Epistemology naturalized. In Ontological relativity and other essays. New York: Columbia University Press. . 1980. Two dogmas of empiricism. In From a logical point of view, 2d edition.

Cambridge: Harvard University Press.

Sellars, Wilfrid. 1963. Empiricism and the philosophy of mind. In $\underline{\text { Science, perception, and }}$ 
reality. London: Routledge and Kegan Paul.

Sen, Amartya. 1981. Poverty and famines. Oxford: Clarendon Press. . 1982. Choice, welfare and measurement. Oxford: Basil Blackwell. . 1984. Economics and the family. In Resources, values, and development. Oxford:

Basil Blackwell. 1987. The standard of living. Cambridge: Cambridge University Press. 